\title{
IMPROVING HOME-BASED CARE IN SOUTHERN AFRICA: AN ANALYSIS OF PROJECT EVALUATIONS
}

\author{
Alana Rosenberg, $M P H^{1}$ \\ Zonke Mabude, $R N / R M, M A^{2}$ \\ Kari Hartwig, $D r P H^{1}$ \\ Sahar Rooholamini, $M P H^{1}$ \\ Dede Oracca-Tetteh, $M P H^{\prime}$ \\ Michael Merson, $M D^{1}$ \\ ${ }^{1}$ Yale University School of Medicine, New Haven, CT, USA \\ ${ }^{2}$ University of the Witwatersrand, fohannesburg, South Africa
}

We describe lessons learned from independent evaluations of nine home-based care ( $\mathrm{HBC}$ ) projects in Lesotho, South Africa and Swaziland. Projects were funded through Bristol-Myers Squibb's Secure the Future (STF) initiative and evaluated through the STF Monitoring and Evaluation Unit (MEU) at Yale University. The objectives of this study were to:

assess the management capacity of the HBC organisations reviewed, concentrating on monitoring and supervision mechanisms

identify innovations in responding to the challenges of delivering care in resource-poor settings, and

explore the nature of linkages between HBC projects and governments.

Specific strategies to assure quality are discussed, as are policy changes necessary to provide system-wide improvements in quality and the integration of HBC. These are particularly important as governments seek ways to use existing resources to make antiretroviral (ARV) roll-outs successful.

More than 25 million people were HIV positive in sub-Saharan Africa at the end of 2004, and during 2004 alone, 2.3 million people died of AIDS.' The HIV/AIDS pandemic is affecting the welfare of nations, communities and families, but its impact begins with the suffering of the infected individual. Before dying, most will experience opportunistic infections, functional and psychological morbidity, and alarmingly under-treated pain. Most often, family members are left to carry the burden of this morbidity. Structured and effective care is not consistently available for all who need it.

The first HBC programmes in Africa for AIDS patients were established in the late 1980s in Zambia and Uganda., The World Health Organization (WHO) describes HBC as placing informal and formal caregivers in the home to 'promote, restore, and maintain a person's maximum level of comfort, function, and health including care toward a dignified death' ( $p$. ix). ${ }^{4}$ In place of acute-care hospitalisation and long-term care institutionalisation, it draws on families and communities to provide hope, support, and high-quality care to ill people in the home including physical, psychosocial, palliative and spiritual activities. The goals of HBC overlap with those of palliative care, as both incorporate spiritual and psychosocial support. However, the latter typically includes care outside as well as within the home, and places a stronger emphasis on pain relief. In southern Africa, common pain control medications such as morphine are not available for patients cared for at home, as inadequate numbers of personnel are qualified to administer such drugs.

In many African countries HBC programmes are being implemented by non-governmental organisations (NGOs) and faith-based organisations (FBOs) to provide services unavailable through health care institutions. In South Africa, for example, the government developed a national HBC strategy because of the lack of hospital beds, inadequate numbers of health professionals, lack of resources for treatment, an emphasis on curable conditions in existing institutions, and cost. ${ }^{5}$ Research has shown that many people prefer to receive care in familiar environments close to family and friends. ${ }^{6,7}$ Furthermore, effective home care has been shown to improve the quality of life of patients as well as their primary caregivers. For families, $\mathrm{HBC}$ may prove more convenient and less expensive than transporting sick family members to the hospital. HBC also provides opportunities for HIV/AIDS education, particularly important for more isolated communities.

Several investigations have expressed the need for more comprehensive evaluative reports of $\mathrm{HBC}$ and clearer guidelines on the development, implementation, monitoring and evaluation of $\mathrm{HBC}$ programmes in developing countries. ${ }^{9-11}$ There is an abundance of related literature, particularly on palliative care, but most of this focuses on Europe and North America. As HBC has emerged as a key strategy in the AIDS 
pandemic in Africa, it is important to build a body of work that includes case studies, lessons learned, and best practices unique to sub-Saharan Africa.

The available literature reveals severe challenges for $\mathrm{HBC}$ in sub-Saharan Africa. Studies cited lack of programme funding ${ }_{1}{ }^{12}$ lack of pain control medication, ${ }^{6,13}$ reliance on volunteers, ${ }_{1}^{14}$ the difficulty of providing care in the context of poverty ${ }_{1}^{15}$ the need to increase coverage of HBC programmes, ${ }_{1}^{16,17}$ and ensuring that these programmes are of high quality and effective. Increases in the number of HIV clients often overshadow the number of accessible caregivers, thus creating a shortage of care and overworked caregivers. Underlying all of these challenges is the lack of integration of HBC programmes into government health care provision..$^{16-19}$ In a 2003 survey of 48 HBC programmes in 14 sub-Saharan African countries, 85\% of programme management reported government endorsement, but almost all also reported absent or problematic palliative care national strategies. ${ }^{18}$

The purpose of this paper is to provide lessons learned from independent evaluations of nine HBC projects in Lesotho, South Africa and Swaziland supported by the Secure the Future (STF) project. The magnitude of the HIV/AIDS pandemic in subSaharan Africa makes the expansion and improvement of HBC a necessity. Using external evaluations from nine diverse $\mathrm{HBC}$ project evaluations, this study explores issues relevant to assuring quality of $\mathrm{HBC}$ projects in southern Africa.

\section{The specific objectives of the study were to:}

assess the management capacity of the HBC organisations reviewed, concentrating on monitoring and supervision mechanisms

identify innovations in responding to the challenges of delivering care in resource-poor settings, and

- explore the nature of linkages between HBC projects and governments.

Our hope was that the results of this study would provide guidance for the implementation of the ARV roll-outs underway or planned in these countries. Specific strategies to assure quality at the project level are discussed, as are policy changes necessary to provide system-wide improvements in quality and the integration of $\mathrm{HBC}$.

\section{METHODS}

We analysed the content of nine $\mathrm{HBC}$ final evaluation reports sponsored by the Bristol-Myers Squibb (BMS) Foundation's STF initiative and overseen by the Monitoring and Evaluation Unit (MEU) of STF at Yale's Center for Interdisciplinary Research on AIDS (CIRA). All evaluations were analysed with permission from the project leadership. While $14 \mathrm{HBC}$ projects were funded by BMS, 4 had not been evaluated by the MEU at the time of the analysis, and for 1 , permission to use the report was not obtained.
The MEU was established through a grant from BMS to provide evaluation services and training in monitoring and evaluation for STF grantees. Regional consultants from a variety of disciplines conducted the evaluations using a participatory approach aimed to meet the needs of project staff and BMS management. Initial planning sessions with project staff were followed by a site visit of 3 - 5 days. Document review, key informant interviews, and focus groups were main data sources. Evaluation reports reviewed the project's strengths, weaknesses and gaps, and provided recommendations and lessons learned. The length of funding for projects was 15 months ( 2 projects), 2 years ( 4 projects), or 3 years ( 3 projects).

Evaluation reports were read by four coders who searched key words (e.g. 'volunteers', 'networks', 'stipends', etc.) and themes (e.g. organisational structure, relationship with government, etc.) relevant to our research questions. These keywords and themes were then integrated into a preliminary coding tree. We then defined each code and used findings from the reports to inform our consolidation of codes into larger categories. The four coders individually coded the same 14-page segment of a report and compared respective results to establish inter-coder reliability. With high levels of agreement, authors then coded reports by hand.

\section{RESULTS}

The project evaluations were carried out in South Africa (7), Swaziland (1) and Lesotho (1) (see Table I). Three of the 9 were implemented by an organisation that identified itself as faithbased. All 9 provided medical care and psychosocial support, and many mentioned that they provided nutritional support (7), information education and communication (6), referrals to other services if needed (6), income-generating activities (5), support for orphans and vulnerable children (5), and skills training (5). Less common were projects that offered spiritual support (2), regular material assistance (2), and voluntary counselling and testing (1). Three organisations had some form of inpatient facility. Those receiving care were in rural, urban and peri-urban areas. While most organisations aimed to provide direct $\mathrm{HBC}$ services, one was an oversight body for $\mathrm{HBC}$ and another was an economic development model implemented in partnership with $\mathrm{HBC}$ providers.

\section{ORGANISATIONAL CAPACITY}

\section{Management}

All the evaluations found areas of management needing improvement. Management challenges included a lack of good governance practices (2), inadequate capacity of the management staff (4), unclear lines of communication and chains of command (2), lack of formal policies and procedures (2), and insufficient management or administrative infrastructure (6). However, some projects excelled in these same areas, with clear staff roles and responsibilities, procedures manuals, dedicated and skilled management staff, 
TABLE I. DESCRIPTION OF THE 9 HBC PROJECTS EVALUATED*

\begin{tabular}{|c|c|c|c|c|c|c|}
\hline Site & Country & $\begin{array}{l}\text { Faith } \\
\text { based }\end{array}$ & $\begin{array}{l}\text { Rural/ } \\
\text { urban }\end{array}$ & $\begin{array}{l}\text { Trained } \\
\text { in } \mathrm{HBC}\end{array}$ & Model & $\begin{array}{l}\text { Caregiver } \\
\text { compensation }\end{array}$ \\
\hline 1 & South Africa & No & Rural & 60 & $\begin{array}{l}\text { NGO collaborates with local } \\
\text { hospital for referrals. HBC } \\
\text { representatives sit on local } \\
\text { management committees in all } \\
\text { areas being served }\end{array}$ & Monthly stipend \\
\hline 2 & South Africa & Yes & $\begin{array}{l}\text { Rural and } \\
\text { urban }\end{array}$ & 110 & $\begin{array}{l}\text { FBO collaborates with churches. } \\
\text { Volunteers trained through ministers } \\
\text { and counsellors of their church. } \\
\text { Caregivers form groups and are } \\
\text { supported by HBC co-ordinator and } \\
\text { consultant social workers }\end{array}$ & None \\
\hline 3 & South Africa & No & $\begin{array}{l}\text { Rural and } \\
\text { urban }\end{array}$ & 214 & $\begin{array}{l}\text { FBO collaborates with area clinics to } \\
\text { support caregivers and refer clients. } \\
\text { Caregivers form groups and are } \\
\text { supported by HBC manager (nurse) }\end{array}$ & Monthly stipend \\
\hline 4 & Swaziland & Yes & $\begin{array}{l}\text { Rural and } \\
\text { urban }\end{array}$ & $\begin{array}{l}120 \\
\text { volunteer } \\
\text { caregivers, } \\
30 \text { parish } \\
\text { nurses }\end{array}$ & $\begin{array}{l}\text { Implementing NGO collaborates } \\
\text { with international partner that } \\
\text { fundraises and provides } \\
\text { medication and technical expertise. } \\
\text { Retired nurses attached to parishes } \\
\text { conduct home visits and provide } \\
\text { professional support to volunteers }\end{array}$ & $\begin{array}{l}\text { Some volunteers } \\
\text { and nurses receive } \\
\text { allowances }\end{array}$ \\
\hline 5 & Lesotho & Yes & Rural & 90 & $\begin{array}{l}\text { National NGO aims to train } \\
\text { professionals on effective HBC who } \\
\text { then train lay counsellors. Project } \\
\text { activities support the national HBC } \\
\text { programme, which forms part of } \\
\text { the existing primary health care } \\
\text { programme }\end{array}$ & None \\
\hline 6 & South Africa & No & Urban & 25 & $\begin{array}{l}\text { Freestanding NGO has sites in city } \\
\text { hospitals and community centers for } \\
\text { collaboration and referrals }\end{array}$ & Monthly stipend \\
\hline 7 & South Africa & No & Peri-urban & 47 & $\begin{array}{l}\text { Academic hospice provides } \\
\text { management and leadership role } \\
\text { to local hospice. Service area divided } \\
\text { into subsections. A professional nurse } \\
\text { supervises caregivers in each subsection }\end{array}$ & Monthly stipend \\
\hline 8 & South Africa & No & Rural & 1046 & $\begin{array}{l}\text { Joint undertaking between the } \\
\text { Provincial Health Department, NGOs, } \\
\text { and co-ordinating bodies to design } \\
\text { and institute an integrated strategy } \\
\text { and governance structures at the } \\
\text { provincial and district levels }\end{array}$ & Monthly stipend \\
\hline 9 & South Africa & No & Peri-urban & NA & $\begin{array}{l}\text { Consortium implementing an } \\
\text { economic development model that } \\
\text { aims to enable households to } \\
\text { generate and acquire resources to } \\
\text { pay for their care requirements, and } \\
\text { subsidise care for those unable to pay } \\
\text { through local enterprise activities. }\end{array}$ & Honoraria \\
\hline
\end{tabular}


and open communication within the organisation cited as strengths.

In 4 projects, strategic planning, financial management, policy issues, work plans and monitoring were handled by an administrative structure separate from the service delivery structure. In all these projects, local management capacity was cited as weak and therefore many management tasks went to consortia or more capable partners. However these partners were further removed, both in distance and focus, from actual service delivery. Evaluators identified a lack of community and unity between administrative and service delivery structures. They recommended improvements in local service delivery structures to make them able to manage and sustain their own work more effectively.

\section{Monitoring}

Monitoring of project process and output indicators needed improvement among all 9 projects evaluated. Seven of the evaluations called for improvements in the monitoring of services; 2 noted that projects had plans in place for implementing a new or improved monitoring system. For different projects, evaluators stated the need for monitoring for a cost-benefit analysis; a quality assurance mechanism verification that activities being carried out were the planned activities funded; data on which to base management decisions; and an evaluation of the impact of caregivers on the well-being of patients.

Several benefits of strong monitoring were observed. Through documentation and monitoring of increased activities, one organisation was able to prove the demand for services and thus secured additional funding for the programme. For 2 projects, needs assessments proved useful; one assisted in allocating appropriate numbers of volunteers per village, and the other helped to revise the project according to gaps identified. The integration of an efficient monitoring system also aided the supervision of caregivers in more than one case. Linking the collection of monitoring data with the disbursement of stipends was one effective strategy employed.

Two organisations had useful partnerships with agencies that provided monitoring and evaluation support. One received assistance from a consultant who developed, through the participation of relevant staff and volunteers, an appropriate set of monitoring tools and then trained staff on how to use the forms. Another organisation partnered with a university to conduct a needs assessment and create a monitoring framework.

\section{Supervision}

Successful monitoring often went hand in hand with effective supervision of caregivers. Supervision was integral to the success of the projects evaluated, and those that made it a main activity were more successful at assuring quality. Supervision by a professional nurse ensured high-quality monitoring at
2 organisations evaluated. Several other successful mechanisms for supervision were reported: regular supervision meetings with caregivers; adequate numbers of nurses to supervise volunteers, described by a staff member as 'the glue that holds the entire operation together' in one project; initiation visits by a nurse to a new patient's home to plan care; and follow-up visits to homes to ask about satisfaction with care offered. One project used retired nurses both to conduct home visits themselves and to support volunteer caregivers, tapping into an available, local, skilled group.

Too often, evaluators found inconsistent supervision. Specific problems included irregular attendance at supervision meetings, especially among volunteers not being compensated adequately; supervision meetings by caregiver request rather than regularly; and a lack of transportation for supervisors to follow up with caregivers and families in rural areas. In one project, the evaluator recommended that further caregivers should not be trained because the organisation did not have the capacity to supervise them adequately.

\section{LIVELIHOOD OPTIONS FOR CAREGIVERS AND CLIENTS}

All HBC projects reviewed operated in resource-poor settings, and both caregivers and clients often faced the day-to-day challenge of surviving with limited access to livelihood. Evaluation reports captured the ways in which projects responded to the income needs of both caregivers and clients.

\section{Caregivers}

The number of caregivers trained in projects ranged from 25 to 1046 individuals. Caregivers were described in many instances as dedicated and ambitious individuals who felt a deep sense of responsibility toward their clients, often as a result of having known or cared for someone who had been ill in the past. The majority of caregivers were young women (under 30 years of age) with little or no previous training in care giving or health care. Only 4 evaluations mentioned criteria for caregivers; 1 programme screened individuals for commitment during a trial period. One evaluator noted marked gender disparities within the HBC programme structure: while the leadership was mostly male, staff and caregivers were mostly female. One evaluator noted that diversifying caregivers by age and gender may make older, male HBC clients feel more at ease.

In all projects, caregivers were volunteers; 7 of these provided some form of financial compensation to caregivers. Some received allowances for meals and transport and/or HBC kits with essential supplies (gloves, linens, medicines, etc.), including clothing and boots. Stipends and allowances were often reported to be insufficient to cover work-related costs and were not regularly disbursed to all caregivers. Of those evaluation reports that specifically reported the stipend amount, the highest stipend mentioned was ZAR500, less than US\$100, per month. HBC kits were reported to be in short supply, and in one programme, kits were entirely missing. 
Some HBC projects tried to address the emotional, professional and practical needs of their caregivers. Two provided counselling for caregivers. One offered a unique solution to the common problem of heavy workload by forming caregiver networks that could be used as a resource for finding help, replacements and greater flexibility with work schedules.

Promotion structure and the opportunity for permanent employment in the community were cited as important incentives for caregivers. In a few projects, caregivers were matched with a professional health care provider in the community to gain knowledge, experience and advice about career development. In another, a promotion structure was created to allow outstanding volunteers to advance (see Fig. 1). All HBC projects offered some form of training to caregivers, and caregivers valued ongoing training, accreditation and skills development programmes.

\section{Clients}

In responding to the holistic needs of clients, the majority of $\mathrm{HBC}$ projects recognised the need for food security and poverty alleviation projects. Eight projects offered material assistance to the neediest families being served, and 3 offered assistance accessing government grants. Five engaged in IGAs with clients and 5 offered skills training. Four of the IGAs made up a significant component of the project, and 1 did not dedicate enough resources to its IGAs and was therefore very limited. Three had dedicated staff or volunteers who received a stipend working specifically on IGAs. Two evaluations noted that IGAs were intended for people living with AIDS (PLWAs), but ended up benefiting community members more generally. Three provided financial assistance to IGAs for start-up materials such as bakery equipment, gardening equipment, and seeds.

Evaluators identified 3 IGA components of projects as achieving 'limited success', 1 as achieving some success, and 1 as a successful aspect of the overall HBC project (see Fig. 2 for project details). IGAs thus presented a challenge for $4 \mathrm{HBC}$ projects. Projects that had dedicated staff and allocated funds for IGAs met with more success than those that did not.

At an urban programme in Johannesburg (Site 7), a 'career path' for volunteers was created as a response to limited funds for stipends. Volunteers started out as unpaid befrienders in hospitals, and were promoted as funds became available if commitment and competence were demonstrated.

\begin{tabular}{|l|l|}
\hline Befriender & $\begin{array}{l}\text { Unpaid } \\
\text { volunteer }\end{array}$ \\
\hline Counsellor & Stipend \\
\hline $\begin{array}{l}\text { HBC } \\
\text { Fieldworker }\end{array}$ & Honorarium \\
\hline Team leader & Paid staff \\
\hline
\end{tabular}

Fig. 1. Creating a 'career path' for volunteers.

\begin{tabular}{|ll|}
\hline Participants: & Women and elderly \\
Mechanisms: & IGA officers hired \\
& Allocated funds \\
& Village committees \\
& Cumulative savings \\
Successes: & Personal empowerment \\
& Donations to households \\
& with orphans \\
& Group unity and cohesion \\
Facilitating factors: & Market opportunities \\
& targeted \\
& Flexibility in project \\
& spending for IGAs (more \\
& than double expected) \\
& \\
&
\end{tabular}

Fig. 2. Successful gardening and candlemaking IGAs at a rural site in Lesotho (Site 6).

\section{PARTNERSHIPS WITH GOVERNMENTS}

A majority of projects described the potential for government involvement in the administration of HBC. Two evaluations of projects, one in South Africa and one in Lesotho, praised the governments' efforts to provide access to best-practice models, training and capacity building opportunities, and financial support. Four projects reported representatives of Departments of Health or Social Development on their boards of directors and advisory boards. Not all agencies reported government involvement. However, when evaluations addressed the issue, all noted that HBC project leadership expressed the need for the government to assume more responsibility on different levels, including the provision of financial assistance, accreditation of training, strengthening the institutional capacity of $\mathrm{HBC}$, and creating a political climate conducive to the efforts of $\mathrm{HBC}$ initiatives.

\section{DISCUSSION}

While all nine projects analysed here were implemented within southern Africa, they were undertaken in vastly different contexts. The mountain villages of Lesotho and the inner city neighbourhoods of Johannesburg would appear to have little in common. Despite major differences in locations, populations served, and national contexts, all projects had the same basic mission: to provide quality home care for PLWAs through trained caregivers in resource-poor and under-served settings. Our findings from these nine diverse projects in three southern African countries illuminate how HBC has been conceived and implemented in the region, obstacles faced in assuring high quality, and how projects have worked to overcome them. The following discussion highlights these findings and recommends policy changes at the funder and national level that could help achieve high-quality, integrated HBC.

\section{BUILDING THE CAPACITY OF ORGANISATIONS}

As the need grows, programme funders and implementers will look to expand $\mathrm{HBC}$ to cover larger geographical areas and 
more patients. However, to do so will require careful attention to the capacity of often new HBC organisations' abilities to effectively manage such expansion, at the local level. At the project level, we have noted that a sustainable HBC programme requires adequate governance, effective communication between partners, access to material resources, institutional support, financial assistance, committed and informed caregivers, and community involvement. Partnerships and consortia may be good solutions to build the capacity of organisations doing $\mathrm{HBC}$, but ultimately funders should realise that success will depend on the ability of projects to increasingly manage their own projects, including financially. Organisations whose finances are managed by parent institutions or other partners may be vulnerable and left with no capacity to manage their own funding should they become independent.

HBC projects must put in place adequate monitoring, evaluation and supervision mechanisms. Collaboration with organisations that have the capacity to provide technical monitoring and evaluation support was a successful strategy in some of the projects evaluated. Funders should seek ways of training management and staff in monitoring and evaluation skills. Information obtained in the process of programme monitoring can be linked to the disbursement of stipends for caregivers. Pre and post evaluations and the development of impact level indicators will help programmes measure effectiveness. For supervision, projects must ensure they have adequate skilled managers or nurses to conduct all supervision, and that regular supervision meetings are held with caregivers. Furthermore, transportation for supervision should be a programme priority. Programmes should not expand beyond their capacity to supervise caregivers in the field.

\section{ENHANCING LIVELIHOOD OPTIONS FOR CAREGIVERS AND CLIENTS}

Effective $H B C$ cannot be delivered without making poverty alleviation for both clients and their caregivers a priority. While volunteers frequently offer their time despite the lack of regular incentives, programme planners, donors and governments should consider the ethics and appropriateness of not adequately compensating people who often come from disadvantaged backgrounds and accept heavy responsibilities of caregiving for the terminally ill. HBC projects that provide caregivers opportunities for advancement to paid positions within the programme and beyond are serving the community in two ways - providing quality $\mathrm{HBC}$ and developing marketable skills. HBC should allow for financial incentives, transportation, medical kits and their re-supply, and provide accessible caregiver support mechanisms in order to boost the morale of caregivers and staff who often face difficult physical and emotional work conditions. Remuneration guidelines should be clearly explained to all volunteers and staff from the outset.

All the projects reviewed faced the tremendous challenge of attempting to provide care in the context of food insecurity and household poverty of clients. Most projects were able to provide some form of material assistance for food security to their most needy clients. While add-on income-generating projects were attempted by many projects, few were economically successful or sustainable. HBC has been sited as a mechanism to reach a community's most vulnerable. Those planning HBC programmes should consider forming partnerships with agencies able to offer economic development possibilities to households in need. In addition, HBC programmes should adequately budget for the start-up funds and external expertise needed if they plan to incorporate an IGA. Finally, a key part of any HBC programme is an efficient medical and social service referral system and assistance in accessing government grants.

\section{STRONGER INTEGRATION OF HBC INTO GOVERNMENT HEALTH CARE PROVISION}

The governments of South Africa, Swaziland, and Lesotho have recognised the importance of $\mathrm{HBC}$ and sought to provide guidance and support to those engaged in HBC. However, HBC needs stronger government co-ordination, integration, and monitoring and evaluation in order to increase quality and coverage. If embedded into a country's national HIVIAIDS plan and adequately linked to the national health care system, HBC will more likely be viewed as a more viable option and funding can be systematically set aside as is the case for other health service areas. Additionally, an established commitment from governments gives projects the firm foundation that may make outside donors more inclined to partner. One important area for government policy development is accreditation for HBC training to assure the quality of instruction and subsequent care in the field. The incorporation of palliative care through the provision of pain control drugs such as morphine is another essential aspect of care that HBC programmes could begin to offer if the supply of drugs could be stabilised through government support. Finally, governments should assess the implications of their remuneration policies for caregivers, or the lack of such policies, to assure fair wages for this necessary service. Given the high demand for HBC and governments' inability to meet this demand, external donors should prioritise $\mathrm{HBC}$ when assisting governments to implement their national HIVIAIDS strategies.

The integration of HBC into government health programmes is particularly important as governments begin to roll out ARVs. NGOs in general, and HBC programmes specifically, have a natural role to play owing to the experience they have gained caring for AIDS patients in their homes over the past decades. Their potential contributions include providing drug education, adherence follow-up, and complementary support, such as food security and counselling to patients on ARVs. Policy makers and those implementing ARV roll-outs should partner with $\mathrm{HBC}$ projects and build their capacity accordingly, as they represent an invaluable resource. The community-based treatment programmes currently being piloted through partnerships between BMS STF and five southern African governments are seeking to do this in an effective manner. 
We extend our appreciation to Sarah Hanck and Alim Manji for assistance in conducting the literature searches; to all project directors who permitted the use of project evaluation reports for this analysis; and to the consultants who conducted these evaluations.

The following evaluation reports from the Bristol-Myers Squibb Secure the Future Monitoring and Evaluation Unit (Yale University) were analysed in the current review: Archdiocese of Cape Town Caring Network Final Evaluation Report. August 2002; Bambisanani HIV/AIDS Project Final Evaluation Report. August 2003; Caritas Swaziland Parish Nurse Programme Final Evaluation Report. August 2003; Christian Health Association of Lesotho Home Based Care Project Final Evaluation Report. November 2004; Community AIDS Response Final Evaluation Report. September 2003; Living with Hope and Meaning in the Face of Illness, Death, and Dying: STH Consortium Final Evaluation Report. March 2002; Naledi Hospice Home Based Care Programme Final Evaluation Report. June 2003; Port Elizabeth Catholic Diocese HIV/AIDS Education Programme Final Evaluation Report. August 2002.

\section{REFERENCES}

1. UNAIDS. 2004 Report on the Global AIDS Epidemic. Geneva: UNAIDS, 2004.

2. PANOS. 1996. Home-based care, not home based neglect. http://www.aegis.com/news/panos/1996/PS960701.html laccessed February 2005).

3. Victor B. What are the lessons learned from the past 15 years of home based care in developing countries? 14th International AIDS Conference, Barcelona, July 2002 (abstract WePeF6642).

4. World Health Organization. Home Based Care and Long Term Care: Home Care Issues at the Approach of the 21st Century from a WHO Perspective: An Annotated Bibliography. Geneva: WHO, 1999.

5. Department of Health, Republic of South Africa. National Guidelines on Home-Based Care/Community-Based Care. Pretoria: DoH: 2001.

6. Kikule E. A good death in Uganda: Survey of needs for palliative care for terminally ill people in urban areas. BMJ 2003; 327: 192-194.

7. Uys L. Aspects of the care of people with HIV/AIDS in South Africa. Public Health Nursing 2003; 20: 271-280.

8. World Health Organization. AIDS Home Care Handbook. Geneva: WHO, 1993.

9. Ndaba-Mbata R, Seloilwe E. Home-based care of the terminally ill in Botswana: Knowledge and perceptions. International Nursing Review 2000; 47: 218-223

10. Singer P, Bowman K. Quality care at the end of life: Should be recognized as a global problem for public health and health systems. BMJ 2002; 324: 1291-1292.

11. Olenja J. Assessing community attitude towards home-based care for people with AIDS (PWAs) in Kenya. Community Health 1999; 24: $187-$ 199

12. Johnson B, Khanna S. Community health workers and home-based care programs for HIV clients. J Natl Med Assoc 2004; 96: 496-502.

13. Murray $S$, Grant E, Grant A, Kendall M. Dying from cancer in developed and developing countries: Lessons from two qualitative interview studies of patients and their carers. BMJ 2003; 326: 368.

14. Akintola O. A Gendered Analysis of the Burden of Care on Family and Volunteer Caregivers in Uganda and South Africa. Durban: Health Economics and HIV/AIDS Research Division, 2004.

15. Fox S. Integrated Community-Based Home Care in South Africa: A Review of the Model Implemented by the Hospice Association of South Africa. Cape Town: Centre for AIDS Development, Research and Education (Cadre) on behalf of The POLICY Project, 2001.

16. UNAIDS. Reaching Out, Scaling Up: Eight Case Studies of Home and Community Care For and By People with HIV/AIDS. Geneva: UNAIDS, 2001.

17. Fru Nsutebu E, Walley J, Mataka E, Fikansa C. Scaling up HIV/AIDS and TB home-based care: Lessons from Zambia. Health Policy and Planning 2001: 16: 240-247.

18. Harding R, Stewart $K$, Marconi K, O'Neill J, Higginson I. Current HIV/AIDS end-of-life care in sub-Saharan Africa: A survey of models, services, challenges and priorities. BioMed Central Public Health 2003; 3 (33)

19. Walker, M, Aceng E, Tindyebwa D, Nabyonga J, Ogwang P, Kiiza P. An assessment of home-based care programs in uganda: their strengths and weaknesses. www.hsph.harvard.edu/takemi/RP213.pdf (accessed June 2004).

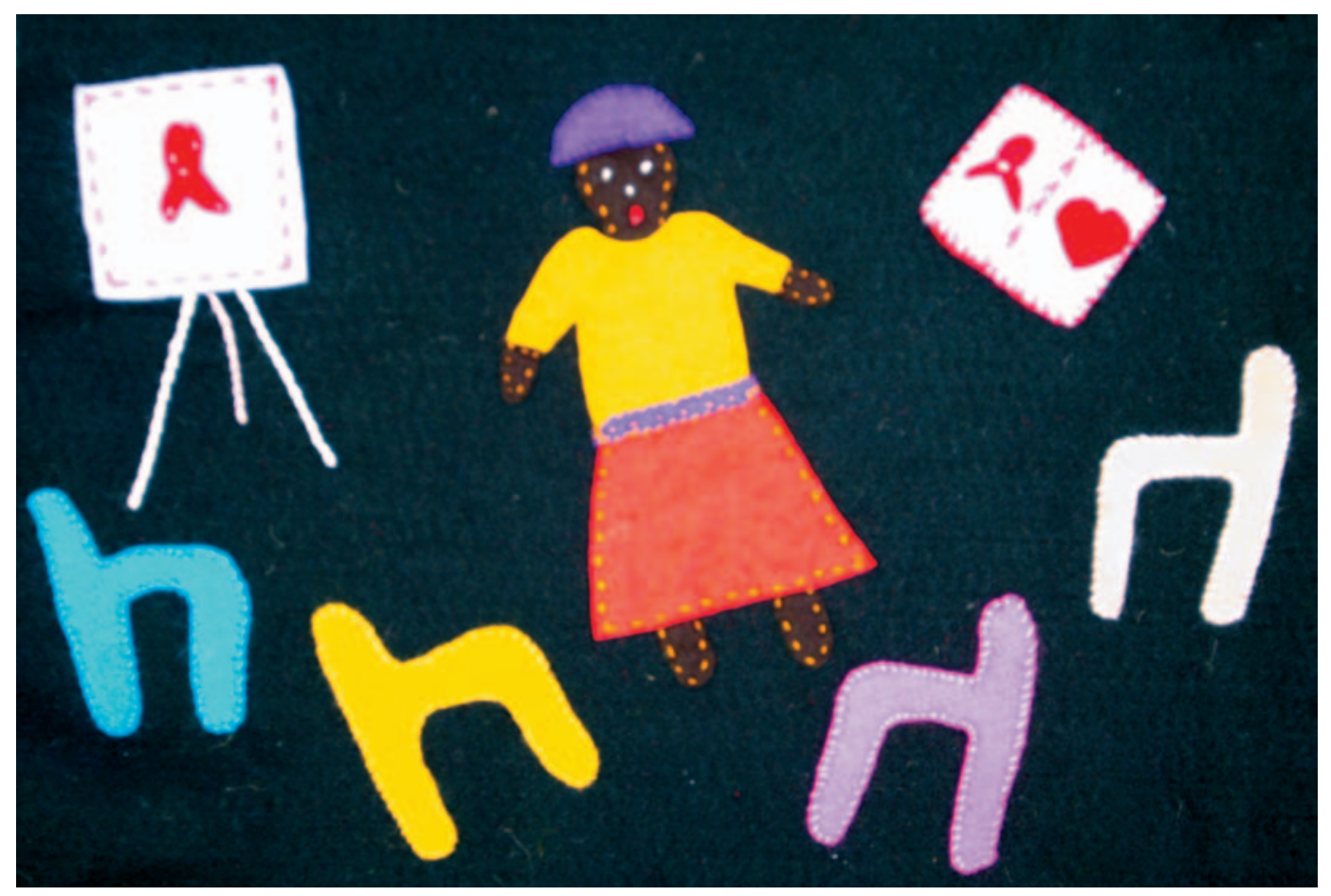

